\title{
ANNOTATION
}

\section{Vision in Motoring}

In a report on "motor vision in safe driving," recently published by the National Society for the Prevention of Blindness, Dr. Laver points out that many accidents occur through (1) failure of the driver to see or interpret a warning signal in time to avoid danger; (2) failure of the driver to determine the exact location of a vehicle, person, or other object in time to avoid collision; (3) failure of the driver to see objects or persons at night.

To the first category belong such conditions as low acuity of vision, restricted field of vision, scotomata, ocular dominance, or the tendency to use one eye more than the other, and lowered attention, which may result in temporary psychic blindness of one or both eyes. The second category deals with such deficiences as poor distance judgment, or muscle imbalance, causing double images. "The driver might see two pairs of headlights in the distance and assume that one car was attempting to pass another, while, in reality there was but one car." The third category deals with blinding lights. Here different persons vary enormously. The young usually stand glaring lights better than the old. The author hopes that the perfection of polarizing glass may solve the glare problem soon. He thinks that the driver should be apprised of his actual potentiality as a driver. "A driver should go no faster than his visibility allows. If the eyes are defective, they should be made as good as possible. There will be plenty of danger from other causes at best." There is no need for us to emphasize the importance of good vision in motoring, including both macular acuity and absence of field restriction. But the best vision in the world will be at a disadvantage in times of over tiredness or stress from any other cause. Accidents on the highway were not unknown before the advent of the motor car and it is obvious that a certain number of accidents are unavoidable. At the same time the numbers in this country are positively appalling and, without being enthusiastic over any further extension of beaurocratic control, we think that the question of the driver's vision has not perhaps received the amount of attention that it deserves. It would not raise so much disquiet in the minds of thinking persons if it were only the driver himself who got maimed or killed. A man may legitimately take some risks if he has only himself to think about. It would be absurd to rule that no one should go mountaineering because accidents have happened in the Alps. Nor should the fact that people have been drowned while boating put a stop to that exercise. 
But the driver is not the only person to be considered; there are his passengers, the occupants of the other vehicle and the pedestrians.

When all is considered the visual acuity of the driver is only one of many points in motoring, but it is a very important one. We certainly think that a driver who has caused a death on the roads by carelessness should be debarred from ever having a licence to drive again. Of course if he kills himself there will be no need for any such restrictions, but the unfortunate thing is that so often it is the opposite party who suffers.

\section{OXFORD OPHTHALMOLOGICAL CONGRESS}

THE twenty-seventh annual meeting of the Congress was held at Keble College on July 7, 8 and 9. The Master, Mr. C. G. Russ Wood presided.

PROF. Hugh CaIRNS (Oxford) opened from the neurosurgical standpoint a discussion on the aetiology, diagnosis and treatment of ocular palsies. He said that the lesions causing ocular palsies are mostly expanding lesions within the orbit and cranium, the clinical picture depending to a remarkable extent upon the speed with which compression or stretching is produced. He referred to the work of Russell Brain on exophthalmic ophthalmoplegia, a progressive condition often following thyroidectomy but also developing spontaneously without thyroid changes. Prof. Cairns concluded by saying there was no. short cut to the mapping of this fascinating field, which could be further explored by the use of radiography, ventriculography and arteriography, and in appropriate cases by surgical exploration.

DR. BERNARD CHAvasse (Liverpool) spoke of the clinical sequelae of ocular palsies. He described the causes and results of over action of muscles and the effects of over action on the muscle itself and on the fasciae of the orbit. Dr. Chavasse discussed the aetiology of congenital torticollis and the diagnosis and treatment of congenital palsies.

Mr. F. A. Williamson-Noble (London) gave an address on contact glasses from the clinical standpoint with a survey of results obtained. The indications for contact glasses were optical, occupational and cosmetic. Optical indications included $(a)$ high myopia, (b) conical cornea, (c) after-effects of mustard-gas burns, (d) hypermetropia and astigmatism, $(e)$ macular disease, $(f)$ faceted cornea. A questionnaire addressed to a large number of patients showed that 50 per cent. of myopes could wear contact glasses for six 